\title{
The Third Millennium and the Consumer: Some Reflections
}

\author{
$\overline{\text { EARL BERGER }}$
}

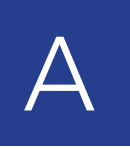

$s$ we enter the third millennium there is a pervasive sense that something is happening with our formerly conforming patients. We even call them "consumers." That phraseology by itself suggests a sea change in how we view the relationship between the medical profession, including the hospital, and those who appear at the door seeking cures and succour. Given these and other changes, it is helpful to step back from the constant pressures of hospital life and reflect for a moment.

Most of us are familiar with evidence of the empowered consumer of health services. Let me briefly review that part of the evidence with which I am most familiar because of our semi-annual surveys of the Canadian population since 1988 and Hay's experience with healthcare reform and hospital restructuring. Some of this evidence, now out of date, has appeared in these pages previously ("Consumers and Hospital Report Cards: First Efforts at Definition,” Spring 1999, p. 4046) and I will summarize.

\section{The Empowered Consumer}

Indications of the empowered consumer are everywhere. The consumer, fuelled by higher levels of education and the sense of autonomy and self-control that follows, and by an unprecedented access to information and choices, is behaving in unprecedented ways. Some examples:

Most Canadians now look beyond the conventional healthcare sector for means to preserve and enhance their well-being. So far, the largest arms of the healthcare sector - physicians and hospitals - do not play a major role in this expanded outlook. At our last investigation in March 1999, 70\% of
Canadians reported using one or more natural health products (NHPs), and two-thirds say that they are not talking to their physicians or pharmacists about it.

Also in March 1999, one in four Canadians (up from about one in 10 in 1993) reported using a chiropractor, naturopath, herbalist or another alternative health provider (AHP) within the previous six months - in this case, two-thirds did talk to their physician about it. However, about half went to an AHP instead of seeing a physician, and about half think the AHP they went to is more knowledgeable about the condition being treated than their physician is.

The trend to increased AHP use seems well established and unlikely to change direction: heavy users of NHPs are the most likely to use AHPs, and the proportion of heavy NHP users has doubled in the past two years.

It is not insignificant that most people using NHPs and AHPs are paying for these products and services out of their own pocket, and that the proportion of NHP users spending $\$ 70$ or more in the previous month has doubled in the past two years. The emphasis is added because these developments are unprecedented over the past 50 years - although some would claim that we are simply returning to the traditional healing practices of the pre-sulfa and penicillin millennia.

In addition, about three million Canadians a year, and increasing, are substituting NHPs for prescription drugs. They report using NHPs instead of the prescription their physician gave them, or more commonly, not going to a physician for a prescription but using a NHP instead; a similar number are substituting NHPs for non-prescription medications. Few of these people discuss the pros and cons with their physicians.

\section{FoOTNOTE:}

Unless otherwise stated, references are to The Berger Monitor and its predecessor, The Canada Health Monitor. The Berger Monitor is a semi-annual national syndicated telephone survey of a representative sample of 2,500 Canadians across the 10 provinces. The Berger Monitor's predecessor, The Canada Health Monitor from which some of the data cited are drawn, was conducted in association with PriceWaterhouseCoopers. The Berger Monitor is designed in consultation with the Hay Health Care Consulting Group, and is administered by Environics Research Group. Topics and questions are selected in consultation with subscribers. 
The rate of growth in the use of NHPs has prompted federal and provincial studies and commissions, the preparation of new federal legislation and regulation, and much controversy among provincial Colleges of Physicians and Surgeons. While the regulators and professions struggle to place NHP use within a framework of public safety, Canadians' use of NHPs continues to soar.

These shifts away from, or the broadening of, mainstream healthcare practices and standards are likely to intensify, leading to demands that mainstream providers "justify" not using the "new" remedies. We can expect increasing pressure from consumers on governments and mainstream providers to accommodate these newer and broader attitudes to health.

\section{Direct-To-Consumer Advertising}

All drug programs in Canada, publicly funded and private health insurance, are under unprecedented and growing pressure from the largest, most sustained marketing and advertising effort the U.S.-based pharmaceutical industry has ever conducted. Because of looser regulations in the United States, pharmaceutical companies there are able to market and advertise their products more freely than before. The result is expenditures of about $\$ 1.3$ billion a year (expected to be $\$ 1.8$ billion in 2000) on direct-to-consumer (DTC) advertising, both television and print. Because of media spillover through magazines and especially television, we can estimate that perhaps $5 \%$ of that - or about $\$ 65$ million - spills over to Canadians. We can argue about the precise amount of dollars involved; whatever that amount, DTC is one of the largest advertising campaigns in Canada. It is certainly among the largest originating outside Canada. By comparison,

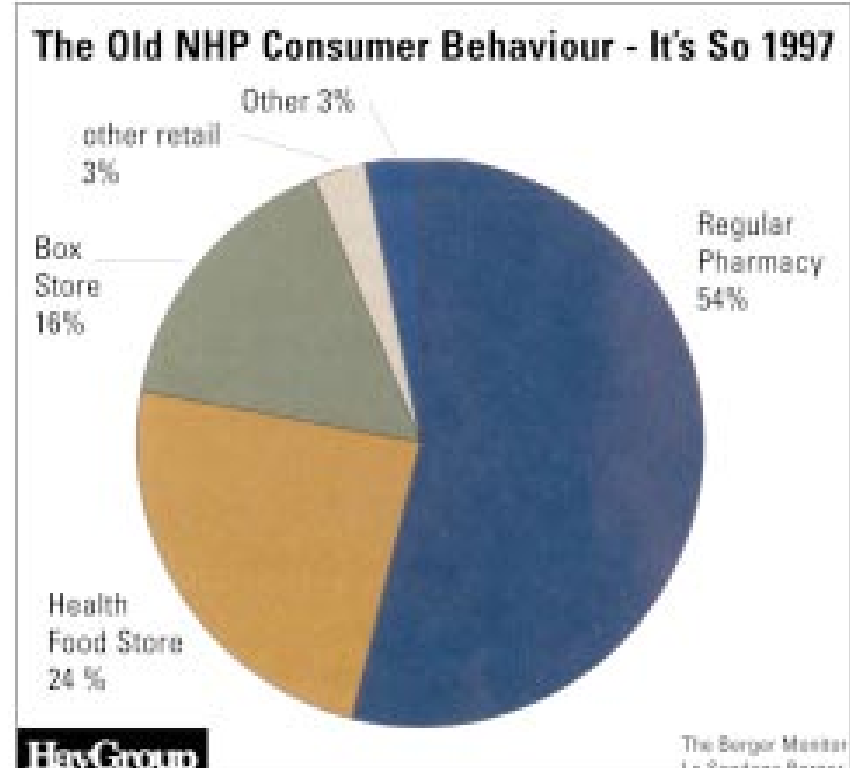

HayGroup Le Sondage Berger
Kraft Foods will spend about $\$ 40$ million this year on advertising in Canada.

The full consequences of this development are not yet clear. There is no doubt, however, that the effects of such a sustained DTC effort, even if it is spillover, will affect the behaviour of, and political pressure from, Canadian consumers.

Two recent examples come to mind. The first is the case of melatonim, of which not necessarily the most extravagant claim was that it was the fountain of youth. Claims could be made for melatonim in the United States, but not in Canada. This generated great pressure on Health Canada to approve its use. It took considerable effort on Health Canada's part to beat back that pressure, arguing that the evidence for melatonim's efficacy had not been, and still is not, demonstrated. Melatonim was followed by Viagra. The willingness and ability of Canadian men of a certain age or physical condition to obtain Viagra from the United States and other jurisdictions with little or no apparent physician involvement is a harbinger of what lies ahead when attractive medications are available in one jurisdiction earlier than in another.

The consumer's ability to obtain some prescription medications with only nominal physician involvement is unprecedented in contemporary medicine. One of the hallmarks of mainstream medicine has been its ability to control access to publicly and privately insured therapies and products, including medications, through the use of administrators and physician gatekeepers. Currently, however, about one in $10 \mathrm{NHP}$ users reports insurance coverage for these products, and the percentage is likely to increase. With respect to prescription medication, it is unlikely that the male consumers' uncontrolled access to Viagra will be one of a kind.

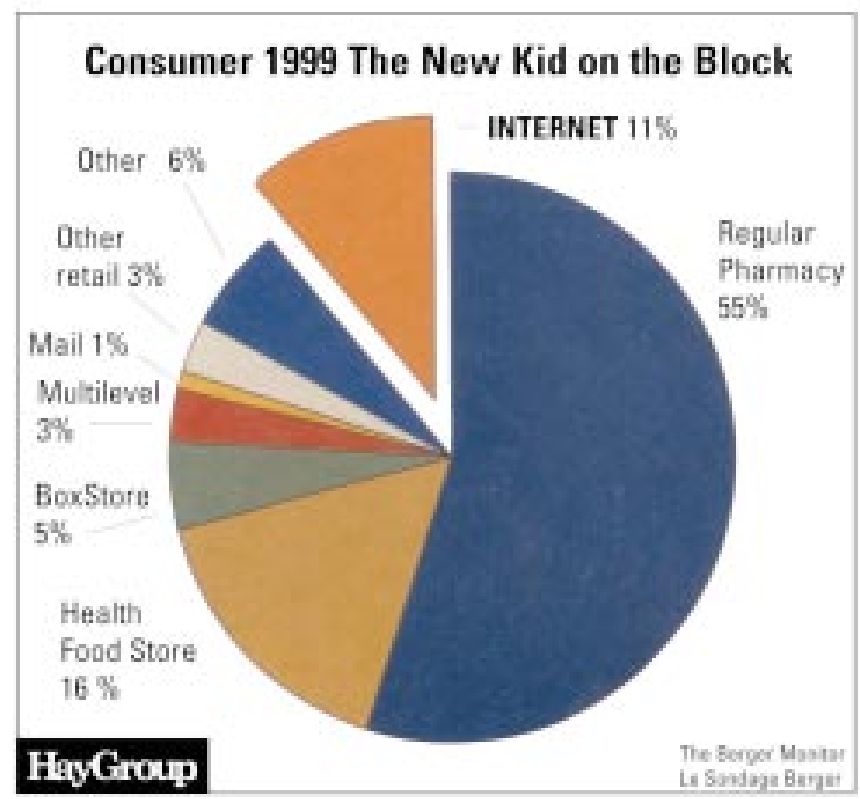




\begin{abstract}
prescri
he patterns of cross-border purchases of prescription medicine are not simple. As the case of Viagra demonstrates, Canadian men are willing and able to purchase drugs in the United States and elsewhere over the Internet and through faxes and telephone rather than wait for the drug to be approved in Canada. In turn, the National Post reports that U.S. seniors travel from Maine to Quebec to purchase prescription drugs at a much lower price than in the United States. In the former case, the Canadian physicians and pharmacists played no gatekeeping role, and U.S. physicians acted as de facto administrators rather than clinicians. In the latter case, the Canadian pharmacist reportedly filled the scripts without a Canadian physician countersigning them and the Quebec governing body is reported to be considering penalties.
\end{abstract}

Likely, we will see more of these end runs, not simply for lifestyle drugs, but also for other medications with a "miracle" halo bestowed by astute marketing and advertising. Mainstream medicine, however much we depend upon it, is losing its ability to manage our access to insured services and products - particularly as the Internet becomes a more widely used tool.

\section{THE INTERNET}

No musings on the new consumer are complete without reference to the Internet. A great deal has been said about how the Internet will revolutionize our lives. These claims should not be taken as hyperbole. The Internet already is impacting on how we define and use health and healthcare services in ways that are not yet well understood. The first characteristic of the Internet is summed up by James Daly, Editor-in-Chief of Business 2.0: "The unadorned truth is really very simple: outside of a petri dish, you won't find anything that grows as fast as the numbers of customers on the Net."

At the time of writing, The Berger Monitor is in the field asking Canadians about their use of the Internet for healthrelated purposes, including the purchase of prescription drugs. What we know already, however, is that the proportion of purchasers of NHPs over the Internet has increased from an infinitesimal percentage two years ago to about $10 \%$ of all NHP purchasers (chart). Because the NHP market is growing rapidly, most retail sectors report experiencing growth in NHP sales. In percentage terms, however, our data suggest most retail sectors have lost ground to the Internet.

Other characteristics of the Internet are relevant here (I am indebted to Business 2.0 for these insights):

Space vanishes; geography disappears. The consumer can search around the world for information and products; the
Internet is filled with infomediaries, search engines designed to provide consumers with information on products and services, prices and descriptions of comparative benefits (the reliability of which varies greatly). As Peter Drucker wrote of the Internet in The Atlantic Monthly, October 1999, "There is only one economy and only one market."

Time collapses; the search takes place immediately; eight seconds is an eternity. Interactivity is critical. There is a huge premium on instant response, and the ability and willingness to change continuously to learn from and adapt to the marketplace in real time.

Implementation expands; it is not simply that the number of Internet customers is increasing rapidly; so are the numbers of Internet health services. One of the many business advisory services on the Internet noted recently that there were about 2,000 health information and service sites on the Web (presumably, only English-language sites). The best known of these are Drkoop, WebMD, Drugstore.com and PlanetX, but there are 1,996 others, all of them anxiously searching for "eyeballs,","stickiness" and "clicks," all of them eagerly offering and encouraging the eyeballs to stick around, and click for something, perhaps anything. There are new players. Unfamiliar names regularly emerge as (they hope) major players in health-related information and services. The scope and energy of these direct and indirect marketing efforts are unprecedented, unmediated and somewhat unnerving.

Dr. Koop, according to the New York Times, offers about 80,000 pages of information to the reader. This much information has never before been put in front of a citizen in so easily accessible a format. The information is unmediated; perhaps unreliable or inappropriate; and there is no physician or pharmacist, unless the consumer chooses to ask, to put the information in the context of the individual consumer's situation. This may be liberating for the consumer, but liberation carries serious consequences, which we are just

A A s examples of new players: Erica Online Inc. said that it signed a three-year $\mathbf{\$ 3}$ million deal with medical information site Medscape Inc. to provide its resources to AOL. Medscape, in which CBS Inc. owns a $35 \%$ stake, has agreed to pay AOL \$33 million over three years. AOL will also get warrants to buy an undisclosed amount of Medscape shares.

Allscripts Inc. (MDRX): "Analysts at CIBC World Markets initiate coverage of Internet healthcare company Allscripts Inc. (MDRX) with a STRONG BUY rating. The company is blazing a trail in the e-healthcare sector with its innovative e-prescription product, TouchScript." 

this information: "And once a thing is put in writing, the composition drifts all over the place, getting into the hands not only of those who understand it, but equally of those who have no business with it; it [see, for example Koop's 80,000 pages] doesn't know how to address the the right people, and not address the wrong."

beginning to discern.

Drucker argues that the Internet is to e-commerce (which includes the health sector) what the railroad was to the Industrial Revolution - "a totally new, totally unprecedented, totally unexpected development." Drucker emphasizes that the Internet gives rise to the knowledge worker, just as the Industrial Revolution gave rise to the industrialist. Drucker stresses the role of the knowledge worker as central to the success of organizations wishing to avoid being diminished by the Internet.

What we do not yet have a good handle on is the Internet's "knowledge consumer." We do not know much, yet, about how this consumer behaves and what it means for the health sector, and for hospitals in particular. My colleagues at Hay report anecdotes of hospitals receiving patients whose families carry with them information and reports obtained over the Internet regarding the latest (sometimes untested, sometimes inappropriate) treatment. This is likely only the tip of something much larger.

These musings end on a note of uncertainty. The present and future are filled with opportunities for individuals to take greater control over their wellness and their health, as well as their healthcare. Similarly, the present and future are filled with opportunities for individuals to mess up their wellness and their health, and their healthcare. Whichever way that goes - and both are likely to happen - the healthcare sector as we know it is almost certainly going to be pulled into new shapes. The glass is either half full or half empty, or both. It is a puzzlement. IQ

Earl Berger, $\mathrm{PhD}$ (Econ) is Managing Director of The Berger Monitor, a semi-annual survey of health issues in Canada, and also Associate Director, Policy, Hay Health Care Consulting Group. He can be reached at:Earl_Berger@haygroup.com 